\title{
The effect of smoking on myeloid-related protein-8 and myeloid-related protein-14
}

\section{Abdullah Seckin ERTUGRUL(a) Hacer SAHIN(b)}

(a) Izmir Katip Celebi University, Faculty of Dentistry, Department of Periodontology, Izmir, Turkey.

(b) Yuzuncu Yil University, Faculty of Dentistry, Department of Periodontology, Van, Turkey.

Declaration of Interests: The authors certify that they have no commercial or associative interest that represents a conflict of interest in connection with the manuscript.

\section{Corresponding Author:}

Abdullah Seckin Ertugrul

E-mail: ertugrulseckin@yahoo.com

DOI: 10.1590/1807-3107BOR-2016.vol30.0051

Submitted: Jul 27, 2015

Accepted for publication: Feb 02, 2016

Last revision: 28 Feb, 2016
Abstract: The aim of this study was to determine the myeloid-related protein-8 and myeloid-related protein-14 levels in the gingival crevicular fluid of smoker patients with generalized aggressive periodontitis $(\mathrm{SAgP})$, smoker patients with chronic periodontitis (SCP), smoker patients with gingivitis (SG-smoker control), non-smoker patients with generalized aggressive periodontitis $(\mathrm{AgP})$, non-smoker patients with chronic periodontitis (CP), and non-smoker patients with gingivitis (G-non-smoker control). The periodontal statuses of the patients were determined by periodontal clinical measurements and radiographical evaluations. The levels of myeloid-related protein- 8 and myeloid-related protein-14 in the gingival crevicular fluid were assessed using enzyme-linked immuno sorbent assay. The myeloid-related protein-8 and myeloid-related protein-14 levels in the gingival crevicular fluid of patients with generalized aggressive periodontitis (non-smoker and smoker) were found to be statistically higher than patients with chronic periodontitis (non-smoker and smoker) and patients with gingivitis (non-smoker and smoker). Myeloid-related protein- 8 and myeloid-related protein-14 levels of non-smokers were significantly higher than smokers in all types of periodontitis and gingivitis. The decreased myeloid-related protein- 8 and myeloid-related protein- 14 level could have prevented the haemostasis of calcium which plays a significant role in the migration of neutrophiles. Smoking affects myeloid-related protein- 8 and myeloid-related protein- 14 levels and may inhibit the antimicrobial efficiency against microorganisms. Due to these reasons smoker generalized aggressive periodontitis patients need to be treated in detail and their maintenance durations should be shortened.

Keywords: Periodontal Diseases; Aggressive Periodontitis; Smoking.

\section{Introduction}

The proliferation and death of cells are controlled by many regulator molecules during the development of organisms. Calcium $\left(\mathrm{Ca}^{2+}\right)$ is one of the key molecules in processes such as nerve impulses, cell growth, neutrophil migration, gene expression, and apoptosis. ${ }^{1}$ Disruption of the $\mathrm{Ca}^{2+}$ balance in tissues results in the development of various diseases. ${ }^{2}$ Intercellular S100 proteins, depending on the tissue, are available as either homologous dimers or different subunits (alpha-beta). By interacting with target proteins, $\mathrm{S} 100$ proteins participate in various functions such as protein phosphorvlation, immune response, differentiation, $\mathrm{Ca}^{2+}$ homeostasis, ${ }^{3}$ 
antimicrobial activity, ${ }^{4}$ and inflammatory reactions ${ }^{5}$ in tissues. It has been determined that one of the S100 proteins, myeloid-related protein (MRP), is a key molecule in neutrophil migration in tissues. Neutrophils are important cell in inflammation. Neutrophil count and neutrophil quantification, give information about the degree of inflammation. ${ }^{6}$

Among the MRPs, S100A8 (MRP-8, calgranulin A, and p8) and S100A9 (MRP-14, calgranulin B, and p14) are members of the $S 100$ family and are defined as $\mathrm{Ca}^{2+}$ binding proteins. ${ }^{7}$ S100A8 and S100A9 form a stable heterodimer (S100A8/A9) in a $\mathrm{Ca}^{2+}$ dependent manner. ${ }^{8}$ High serum concentrations of MRPs have been found in chronic periodontal diseases ${ }^{9,10}$ and chronic bronchitis. ${ }^{11}$ MRP-8 and MRP-14 mediate regulatory antiproliferative, antitumoral, antimicrobial, and antinociceptive activities. ${ }^{12}$

Nicotine, is one of the destructive materials to contact with periodontal tissues. Smoking cigarettes decreases the protective effect of the epithelium against microorganisms. ${ }^{13}$ In some studies, it is mentioned that nicotine or smoking cigarettes could inhibit the expression of antimicrobial peptides from epithelium tissue. ${ }^{14,15}$ Some studies found that nicotine stimulates upregulated expression of antimicrobials in a human keratinocyte cell line. ${ }^{16}$

Because discovering the relationship between periodontal diseases, smoking, MRP-8, and MRP-14 might be helpful in understanding the pathogenesis of periodontal diseases, the aim of this study was to compare MRP-8 and MRP-14 levels in gingival crevicular fluid (GCF) using enzyme-linked immuno sorbent assay (ELISA) methods in smoker patients with generalized aggressive periodontitis, smoker patients with chronic periodontitis, smoker patients with gingivitis (smoker-control group), non-smoker patients with generalized aggressive periodontitis, non-smoker patients with chronic periodontitis, and non-smoker patients with gingivitis (non-smoker-control group).

\section{Methodology}

a total of 126 patients were included in this research study according to the following criteria: no cardiovascular disease, no chronic kidney disease, not receiving any periodontal treatment in the previous 6 months, not taking antibiotics or medicines affecting the immune system in the previous 6 months, and having at least 20 teeth. All of the patients read and signed informed consent forms and read the Helsinki Declaration before participating in the study. For this study, approval from the Human Ethics Research Committee of Yuzuncu Yil University (no. YYU-070511) was provided. The smoking history of the patients was evaluated by asking the patient's questions, and the patients were divided into groups based on their responses. If the patient smoked more than 10 cigarettes/day, then he/she was classified as a smoker; if he/she had never smoked, then he/she was classified as a non-smoker. Whether patients who smoked 1-9 cigarettes/day were excluded from the study. The patients were classified as follows: 21 smoker patients with generalized aggressive periodontitis (12 male, 9 female) (SAgP); 21 smoker patients with chronic periodontitis (11 male, 10 female) (SCP); 21 smoker patients with gingivitis (9 male, 12 female) (SG) (smoking-control group), 21 non-smoker patients with generalized aggressive periodontitis (12 male, 9 female) (AgP), 21 non-smoker patients with chronic periodontitis (11 male, 10 female) $(\mathrm{CP})$, and 21 non-smoker patients with gingivitis (11 male, 10 female) (G) (non-smoking-control group). The patients were selected in accordance with the clinical and radiographic criteria proposed by the 1999 International Workshop for a Classification of Periodontal Diseases and Conditions. ${ }^{17}$ Clinical periodontal measurements, including periodontal status, were conducted by measuring bleeding on probing $(\mathrm{BOP})$, plaque index $(\mathrm{Pl}){ }_{1}^{18}$ gingival index $(\mathrm{GI}){ }^{19}$ probing depth (PD), and clinical attachment loss (CAL). All of the measurements were performed by a calibrated examiner (ASE).

Generalized aggressive periodontitis group (AgP): At the time of the oral examination, these patients were between 16 and 30 years of age and had at least 20 natural teeth, including a minimum of 6 incisors and/or first molars with at least 1 site with PD and CAL $>5 \mathrm{~mm}$, as well as a minimum of 6 teeth other than the first molars and incisors and at least one site with PD and LCAL $>5$ millimeters.

Chronic periodontitis group (CP): At the time of the oral examination, this group had inflammation in 
the gingiva, microbial dental plaque formation, and vertical and horizontal bone loss on the radiographic examination, $\geq 5 \mathrm{~mm}$ PD in at least 6 sites of at least 4 teeth with one root, and $\geq 4 \mathrm{~mm}$ of CAL.

GCF samples were taken from four Ramfjord sample teeth (teeth 1.6, 2.4, 3.6, and 4.4; if not in oral cavity, 1.1 and 4.1). No-periodontal treatments were performed on the patients prior to obtaining the GCF samples. The surfaces of the teeth were isolated with cotton tampons and dried with pressurized air to ensure that there was no accumulation of plaque at the sampling area. Supragingival plaque was removed using sterile curettes. Special attention was paid to ensure that the paper strips (Periopaper Oraflow, New York, USA) were not contaminated with blood or saliva. Paper strips contaminated with blood or saliva, were discarded. To maintain standardization, the GCF volume $(\mu \mathrm{l})$ of each strip was measured using an electronic device (Periotron 8000, Oraflow, New York, USA) after keeping the strips in the gingival sulcus for 30 seconds. The collected strips were placed in Eppendorf tubes containing $500 \mu \mathrm{l}$ phosphate buffer solution, and the tubes were stored at $-80^{\circ} \mathrm{C}$.

A commercial MRP-8 ELISA kit (MRP-8 ELISA kit, MBL, Woburn, USA) was used to determine the MRP-8 level and an MRP-14 ELISA kit (MRP-14 ELISA kit, MBL, Woburn, USA) was used to determine the MRP-14 level. To prepare the standards, the kit stock standard was diluted according to the manufacturer's instructions. GCF samples were added according to the procedures defined in the ELISA kits. The ELISA plates were then immediately assessed at 450 $\mathrm{nm}$ in an ELISA-reader (Microplate Reader Biotek, Winooski, USA). Samples from all of the patients were placed in separate aliquots, which had been separately enumerated. Four paper strips taken from different areas of each patient, were placed inside the separately numbered aliquots (one paper strip at one aliquot). To prevent mistakes, rather than taking only one sample from each patient, four samples were obtained from each patient and the mean average was calculated. The sample values were calculated using a computer program to determine the MRP-8 and MRP-14 levels.

The data were analyzed using a statistical package computer program. First, a normality test was used.
The clinical periodontal measurements, MRP-8, and MRP-14 levels did not show normal distributions, and thus non-parametrical tests (Mann-Whitney $\mathrm{U}$ test) were used in the statistical analyses of these data. Spearman's rank correlation analysis was used to determine the relationship between clinical periodontal measurements and the MRP- 8 and MRP-14 levels in GCF. Power analysis was employed for the present study by nQuery Advisor package program. Sample/patients size for per-group is 21 and the power of the study is 95 .

\section{Results}

When the periodontal clinical measurements of all mouth were evaluated, the PI, GI, PD, BOP, and CAL values in the G groups (smoker and nonsmoker) were found to be statistically lower than $\mathrm{CP}$ and AgP (smoker and non-smoker) groups ( $\mathrm{p}<$ 0.05 ). When these results were evaluated as being site specific (Evaluating the tooth from which gingival crevicular fluid samples together with the mesial and distal tooth.) the PI, GI, PD, BOP, and CAL values in the $G$ groups (smoker and non-smoker) were found to be statistically lower than $\mathrm{CP}$ and $\mathrm{AgP}$ (smoker and non-smoker) groups ( $\mathrm{p}<0.05$; Table 1-2). The periodontal clinical measurements of all mouth were evaluated, the PI, GI, PD, BOP, and CAL values in the $\mathrm{CP}$ groups (smoker and non-smoker) were found to be statistically lower than AgP (smoker and non-smoker) groups $(\mathrm{p}<0.05)$. When these results were evaluated site specifically the PI, GI, PD, BOP, and $\mathrm{CAL}$ values in the $\mathrm{CP}$ groups (smoker and nonsmoker) were found to be statistically higher than AgP (smoker and non-smoker) groups ( $\mathrm{p}<0.05$; Table 1-2).

The PI, GI, PD, BOP, and CAL values in the SAgP group were not statistically different than in the AgP group ( $p>0.05$; Table 1-2). Similarly a statistical difference could not be observed in terms of clinical measurements between $\mathrm{CP}$ and SCP groups and between $G$ and SG groups ( $p>0.05$; Table 1-2). When these results were evaluated site specifically the PI, GI, $\mathrm{PD}$, and CAL values in the SAgP group was found to be statistically higher than in the AgP group $(\mathrm{p}<0.05)$. However BOP values in the AgP group was found to be statistically higher than in the SAgP group $(\mathrm{p}<0.05$; Table 2). Similarly it has been found that the clinical 
The effect of smoking on myeloid-related protein-8 and myeloid-related protein-14

Table 1. Clinical Periodontal Measurements (All Mouth) and Age of the Study Groups (Mean \pm Standard deviation)

\begin{tabular}{|c|c|c|c|c|c|c|c|}
\hline & $\begin{array}{c}\text { Smoker patients } \\
\text { with generalized } \\
\text { aggressive } \\
\text { periodontitis (SAgP) }\end{array}$ & $\begin{array}{l}\text { Smoker patients } \\
\text { with chronic } \\
\text { periodontitis } \\
\text { (SCP) }\end{array}$ & $\begin{array}{c}\text { Smoker } \\
\text { patients with } \\
\text { gingivitis (SG) } \\
\text { (Control) }\end{array}$ & $\begin{array}{l}\text { Non-smoker patients } \\
\text { with generalized } \\
\text { aggressive } \\
\text { periodontitis }(\mathrm{AgP})\end{array}$ & $\begin{array}{c}\text { Non-smoker } \\
\text { patients } \\
\text { with chronic } \\
\text { periodontitis (CP) }\end{array}$ & $\begin{array}{c}\text { Non-smoker } \\
\text { patients with } \\
\text { gingivitis(G) } \\
\text { (Control) }\end{array}$ & \multirow[t]{2}{*}{$p$-value } \\
\hline & (n: 21) & (n: 21) & (n: 21) & (n: 21) & (n: 21) & (n: 21) & \\
\hline AGE & $26.4 \pm 4.12$ & $33.1 \pm 5.23$ & $27.8 \pm 5.21$ & $25.9 \pm 2.31$ & $31.9 \pm 5.01$ & $28.3 \pm 6.32$ & \multirow{2}{*}{$<0.05$} \\
\hline$M n \pm S d$ & $\# €$ & $* ¥ \& \beta$ & $\# €$ & $\# € \& \beta$ & $* ¥ \& \beta$ & $\# €$ & \\
\hline $\mathrm{PI}$ & $2.01 \pm 0.23$ & $1.84 \pm 0.29$ & $1.51 \pm 0.45$ & $1.99 \pm 0.31$ & $1.81 \pm 0.27$ & $1.38 \pm 0.88$ & \multirow{2}{*}{$<0.05$} \\
\hline $\mathrm{Mn} \pm \mathrm{Sd}$ & $\# € \& B$ & $* ¥ \& \beta$ & $* ¥ \# €$ & $\# € \& B$ & $* ¥ \& \beta$ & $* ¥ \# €$ & \\
\hline GI & $1.94 \pm 0.23$ & $1.81 \pm 0.34$ & $1.44 \pm 0.45$ & $1.92 \pm 0.45$ & $1.80 \pm 0.51$ & $1.31 \pm 0.55$ & \multirow{2}{*}{$<0.05$} \\
\hline $\mathrm{Mn} \pm \mathrm{Sd}$ & $\# € \& \beta$ & $* ¥ \& \beta$ & $* ¥ \# €$ & $\# € \& \beta$ & $* ¥ \& \beta$ & $* ¥ \# €$ & \\
\hline $\mathrm{PD}(\mathrm{mm})$ & $3.97 \pm 0.46$ & $3.53 \pm 0.31$ & $2.01 \pm 0.9$ & $3.89 \pm 0.61$ & $3.52 \pm 0.47$ & $1.89 \pm 0.23$ & \multirow{2}{*}{$<0.05$} \\
\hline $\mathrm{Mn} \pm \mathrm{Sd}$ & $\# € \& \beta$ & $* ¥ \notin ß$ & $* ¥ \# €$ & $\# € \& B$ & $* ¥ \notin \&$ & $* ¥ \# €$ & \\
\hline $\mathrm{CAL}(\mathrm{mm})$ & $4.04 \pm 0.63$ & $3.74 \pm 0.55$ & $2.04 \pm 0.6$ & $4.01 \pm 0.89$ & $3.79 \pm 0.51$ & $1.9 \pm 0.33$ & \multirow{2}{*}{$<0.05$} \\
\hline $\mathrm{Mn} \pm \mathrm{Sd}$ & $\# € \& B$ & $* ¥ \& \beta$ & $* ¥ \# €$ & $\# € \& ß$ & $* ¥ \& \beta$ & $* ¥ \# €$ & \\
\hline BOP $\%$ & $82.23 \pm 7.43$ & $74.51 \pm 9.81$ & $62.21 \pm 4.33$ & $81.60 \pm 9.53$ & $75.90 \pm 7.7$ & $65.34 \pm 7.1$ & \multirow{2}{*}{$<0.05$} \\
\hline $\mathrm{Mn} \pm \mathrm{Sd}$ & $\# € \& B$ & $* ¥ \notin \& \beta$ & $* ¥ \# €$ & $\# € \& ß$ & $* ¥ \notin \&$ & $* ¥ \# €$ & \\
\hline
\end{tabular}

Pl: plaque index; Gl: gingival index; PD; probing depth; CAL: clinical attachment loss; BOP: bleeding on probing, Mn: Mean; Sd: Standerd derivation.

*Significantly different from SAgP, $\mathrm{p}<0.05$ (Mann-Whitney U test).

\#Significantly different from SCP, $p<0.05$ (Mann-Whitney U test).

$¥$ Significantly different from AgP, $p<0.05$ (Mann-Whitney $\mathrm{U}$ test).

ESignificantly different from CP, $\mathrm{p}<0.05$ (Mann-Whitney $\mathrm{U}$ test).

\&Significantly different from SG, $\mathrm{p}<0.05$ (Mann-Whitney U test).

BSignificantly different from $G, p<0.05$ (Mann-Whitney U test).

Table 2. Clinical Periodontal Measurements (Site Specific) of the Study Groups (Mean \pm Standard deviation).

\begin{tabular}{|c|c|c|c|c|c|c|c|}
\hline & $\begin{array}{c}\text { Smoker patients } \\
\text { with generalized } \\
\text { aggressive } \\
\text { periodontitis (SAgP) }\end{array}$ & $\begin{array}{l}\text { Smoker patients } \\
\text { with chronic } \\
\text { periodontitis } \\
\text { (SCP) }\end{array}$ & $\begin{array}{c}\text { Smoker } \\
\text { patients with } \\
\text { gingivitis (SG) } \\
\text { (Control) }\end{array}$ & $\begin{array}{l}\text { Non-smoker patients } \\
\text { with generalized } \\
\text { aggressive } \\
\text { periodontitis (AgP) }\end{array}$ & $\begin{array}{l}\text { Non-smoker } \\
\text { patients } \\
\text { with chronic } \\
\text { periodontitis (CP) }\end{array}$ & $\begin{array}{l}\text { Non-smoker } \\
\text { patients with } \\
\text { gingivitis (G) } \\
\text { (Control) }\end{array}$ & \multirow[t]{2}{*}{$\mathrm{p}$-value } \\
\hline & (n: 21) & (n: 21) & (n: 21) & (n: 21) & (n: 21) & (n: 21) & \\
\hline $\mathrm{Pl}$ & $2.21 \pm 0.32$ & $2.01 \pm 0.15$ & $1.41 \pm 0.24$ & $2.05 \pm 0.25$ & $1.90 \pm 0.43$ & $1.30 \pm 0.46$ & \multirow{2}{*}{$<0.05$} \\
\hline $\mathrm{Mn} \pm \mathrm{Sd}$ & $\# € \# \& ß$ & $* ¥ € \& ß$ & $* ¥ \# € \beta$ & ${ }^{*} \# € \& ß$ & $* \# \# \& B$ & *¥\#€\& & \\
\hline GI & $2.18 \pm 0.34$ & $2.00 \pm 0.45$ & $1.41 \pm 0.25$ & $2.04 \pm 0.21$ & $1.88 \pm 0.25$ & $1.32 \pm 0.33$ & \multirow{2}{*}{$<0.05$} \\
\hline$M n \pm S d$ & $\# € \# \& B$ & $* ¥ € \& ß$ & $* ¥ \# € \beta$ & *\#€\&ß & *\#\#\&B & $* ¥ \# € \&$ & \\
\hline $\mathrm{PD}(\mathrm{mm})$ & $3.86 \pm 0.54$ & $3.21 \pm 0.33$ & $1.99 \pm 0.81$ & $3.59 \pm 0.44$ & $3.08 \pm 0.66$ & $1.78 \pm 0.12$ & \multirow{2}{*}{$<0.05$} \\
\hline $\mathrm{Mn} \pm \mathrm{Sd}$ & $\# € \# \& B$ & $* ¥ € \& ß$ & $* ¥ \# € ß$ & *\#€\&B & $* \# \# \& B$ & *\#\#€\& & \\
\hline $\mathrm{CAL}(\mathrm{mm})$ & $3.94 \pm 0.43$ & $3.24 \pm 0.44$ & $2.00 \pm 0.5$ & $3.51 \pm 0.66$ & $3.11 \pm 0.23$ & $1.6 \pm 0.45$ & \multirow{2}{*}{$<0.05$} \\
\hline$M n \pm S d$ & $\# € \neq \& \beta$ & $* ¥ € \& ß$ & $* ¥ \# € ß$ & ${ }^{*} \# € \& ß$ & *\#\#\&ß & *\#\#€\& & \\
\hline ВОР\% & $65.34 \pm 8.21$ & $61.42 \pm 8.54$ & $23.12 \pm 3.44$ & $72.80 \pm 10.4$ & $70.81 \pm 8.7$ & $25.43 \pm 8.2$ & \multirow{2}{*}{$<0.05$} \\
\hline$M n \pm S d$ & $\# € \& ß \#$ & $* € \# \& B$ & $* ¥ \# € \beta$ & ${ }^{*} \# € \& ß$ & *\#\#\&B & $* \& \# \# €$ & \\
\hline
\end{tabular}

PI: plaque index; Gl: gingival index; PD: probing depth; CAL: clinical attachment loss; BOP: bleeding on probing; Mn: Mean; Sd: standard Derivation.

*Significantly different from SAgP, $p<0.05$ (Mann-Whitney U test). \#Significantly different from SCP, $p<0.05$ (Mann-Whitney U test). $¥$ Significantly different from AgP, $p<0.05$ (Mann-Whitney $U$ test).

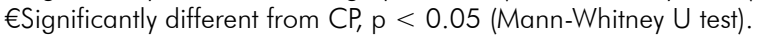
\&Significantly different from SG, $p<0.05$ (Mann-Whitney $U$ test).

BSignificantly different from $G, p<0.05$ (Mann-Whitney U test). 
periodontal index data besides $\mathrm{BOP}$ of SCP patients were found to be statistically higher in CP patients.

The MRP-8 and MRP-14 levels in the GCF of all of the groups are presented in Figure 1 and 2. When these results were assessed, the MRP-8 and MRP-14 levels in the GCF of the AgP group were found to be statistically higher than in the SAgP group and the MRP-8 and MRP-14 levels in the GCF of the CP group were found to be statistically higher than in the SCP group $(p<0.05)$. The MRP-8 and MRP-14 levels were found to be the lowest in the SG group and highest in the AgP group.

The correlations between the periodontal clinical measurements and the MRP-8 and MRP-14 levels in GCF are shown in Table 3. When the correlations between periodontal clinical measurements of patients in the SAgP group and the levels of MRP-8 and MRP-14 were examined, it was determined that there was a positive weak correlation between the MRP-8 and MRP-14 levels and periodontal clinical measurements, but the results were not statistically different $(p>0.01)$. When the correlation between the periodontal clinical measurements and the MRP-8 and MRP-14 levels in patients from the AgP group were examined, it was observed that there was a positive, weak correlation between the MRP-8 and MRP-14 levels and periodontal clinical measurements. But the results were not statistically different $(p>0.01)$. When the correlation between the periodontal clinical measurements and the MRP-8 and MRP-14 levels in patients from the SCP group were examined, similar to the other groups, it was determined that there was a positive, weak correlation between the MRP- 8 and MRP-14 levels and periodontal clinical measurements, but the results were not statistically different $(p>0.01)$. When the correlation between the periodontal clinical measurements and the MRP-8 and MRP-14 levels in patients from the $\mathrm{CP}$ group was examined, it was observed that there was a positive, weak correlation between the MRP-8 and MRP-14 levels and periodontal clinical measurements. When all of the correlation results had been evaluated, it was determined that the MRP-8 and MRP-14 levels increase with the increase of periodontal clinic measurements in individuals within the $\mathrm{CP}$ and $\mathrm{AgP}$ groups. These data have not been found to be statistically significant.

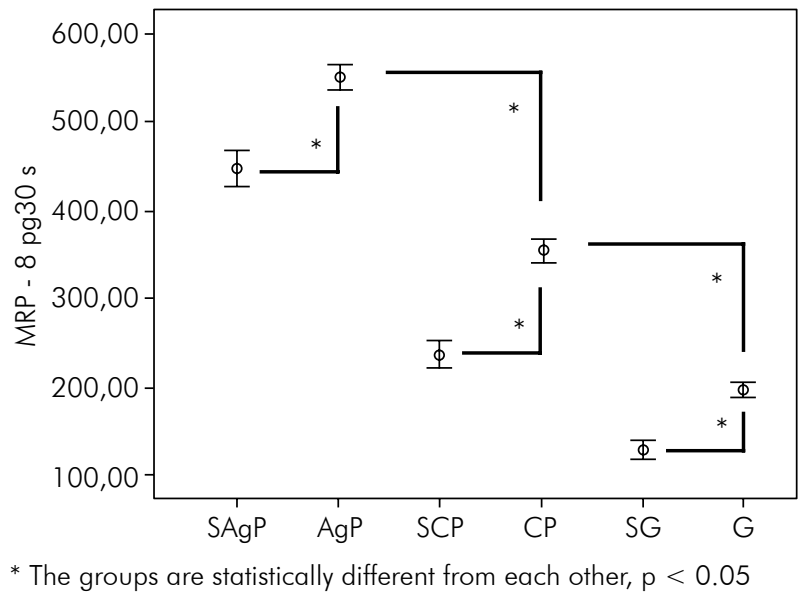

Figure 1. The comparison of the myeloid-related protein-8 (MRP-8) total levels of patients diagnosed with generalized aggressive periodontitis (SAgP) with smoking, chronic periodontitis $(\mathrm{SCP})$ with smoking, gingivitis $(\mathrm{SG})$ with smoking, generalized aggressive periodontitis $(\mathrm{AgP})$ without smoking, chronic periodontitis $(C P)$ without smoking, and gingivitis $(G)$ without smoking.

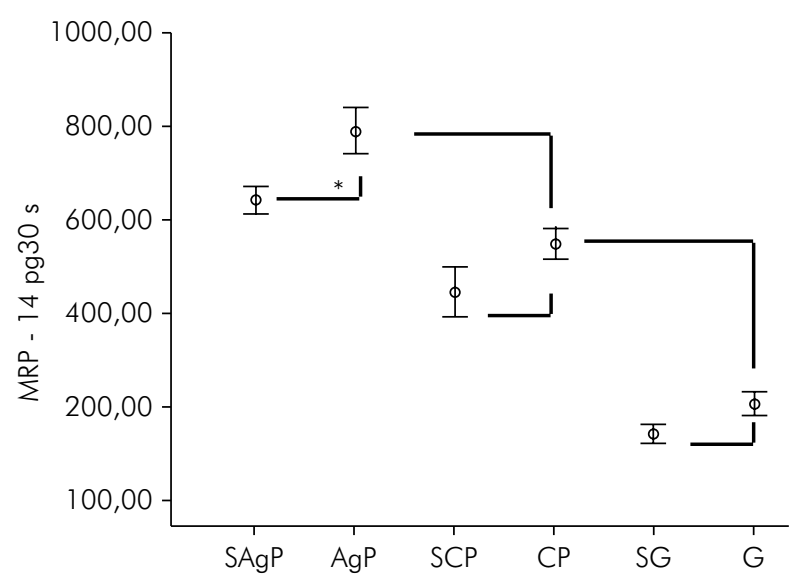

* The groups are statistically different from each other, $p<0.05$

Figure 2. The comparison of the myeloid-related protein-14 (MRP14) total levels of patients diagnosed with generalized aggressive periodontitis (SAgP) with smoking, chronic periodontitis (SCP) with smoking, gingivitis (SG) with smoking, generalized aggressive periodontitis $(\mathrm{AgP})$ without smoking, chronic periodontitis $(\mathrm{CP})$ without smoking, and gingivitis $(G)$ without smoking.

\section{Discussion}

In this study, the MRP-8 and MRP-14 levels in the SAgP, AgP, SCP, CP, SG, and G patients were determined and the results were compared with periodontal clinical measurements. This study is the first study that evaluates patients from smoker 
Table 3. Correlations Between MRP-8, MRP-14 Levels, and Clinical Periodontal Measurements of Study Groups (Spearman's rank correlation analysis).

\begin{tabular}{|c|c|c|c|c|c|c|c|c|c|c|c|c|}
\hline & \multicolumn{2}{|c|}{$\begin{array}{l}\text { Smoker patients with } \\
\text { generalized aggressive } \\
\text { periodontitis (SAgP) }\end{array}$} & \multicolumn{2}{|c|}{$\begin{array}{l}\text { Smoker patients with } \\
\text { chronic periodontitis } \\
\text { (SCP) }\end{array}$} & \multicolumn{2}{|c|}{$\begin{array}{l}\text { Smoker patients } \\
\text { with gingivitis (SG) }\end{array}$} & \multicolumn{2}{|c|}{$\begin{array}{l}\text { Non-smoker patients with } \\
\text { generalized aggressive } \\
\text { periodontitis (AgP) }\end{array}$} & \multicolumn{2}{|c|}{$\begin{array}{c}\text { Non-smoker } \\
\text { patients with chronic } \\
\text { periodontitis }(\mathrm{CP})\end{array}$} & \multicolumn{2}{|c|}{$\begin{array}{l}\text { Non-smoker } \\
\text { patients with } \\
\text { gingivitis }(G)\end{array}$} \\
\hline & MRP-8 & MRP-14 & MRP-8 & MRP-8 & MRP-8 & MRP-14 & MRP-8 & MRP-14 & MRP-8 & MRP-14 & MRP-8 & MRP-14 \\
\hline $\mathrm{Pl}-\mathrm{r}$ & 0.261 & 0.299 & 0.146 & 0.093 & 0.134 & 0.234 & 0.377 & 0.285 & 0.143 & 0.386 & 0.123 & 0.265 \\
\hline$p$-value & 0.191 & 0.158 & 0.341 & 0.536 & 0.125 & 0.209 & 0.132 & 0.174 & 0.348 & 0.129 & 0.167 & 0.162 \\
\hline Gl-r & 0.222 & 0.236 & 0.194 & 0.055 & 0.274 & 0.264 & 0.299 & 0.298 & 0.234 & 0.268 & 0.221 & 0.241 \\
\hline$p$-value & 0.261 & 0.502 & 0.256 & 0.906 & 0.144 & 0.532 & 0.166 & 0.789 & 0.213 & 0.186 & 0.134 & 0.534 \\
\hline PD-r & 0.137 & 0.143 & 0.223 & 0.331 & 0.256 & 0.301 & 0.298 & 0.301 & 0.269 & 0.285 & 0.212 & 0.235 \\
\hline$p$-value & 0.601 & 0.496 & 0.222 & 0.150 & 0.121 & 0.173 & 0.166 & 0.165 & 0.185 & 0.174 & 0.135 & 0.189 \\
\hline CAL-r & 0.183 & 0.146 & 0.325 & 0.251 & 0.333 & 0.235 & 0.301 & 0.299 & 0.301 & 0.234 & 0.270 & 0.245 \\
\hline$p$-value & 0.501 & 0.486 & 0.153 & 0.198 & 0.186 & 0.201 & 0.165 & 0.166 & 0.165 & 0.213 & 0.178 & 0.123 \\
\hline BOP-r & 0.269 & 0.234 & 0.082 & 0.193 & 0.245 & 0.234 & 0.268 & 0.377 & 0.357 & 0.183 & 0.198 & 0.256 \\
\hline $\mathrm{p}$-value & 0.188 & 0.194 & 0.607 & 0.258 & 0.190 & 0.164 & 0.186 & 0.132 & 0.135 & 0.272 & 0.186 & 0.145 \\
\hline
\end{tabular}

PI: plaque index; GI: gingival index; PD: probing depth; CAL: clinical attachment loss; BOP: bleeding on probing; r: correlation coefficient.

and non-smoker AgP, CP, and G (control) groups and compares their MRP-8 and MRP-14 amounts in GCF.

In $\mathrm{AgP}$ patients, while the patients' insufficient immune system response to bacterial attack plays a role in the onset of disease, clinical progress becomes more severe with the addition of environmental and acquired risk factors. ${ }^{20}$ Another factor that increases the severity of the clinical progress of the disease is the alteration of microbial flora toward pathogenic microorganisms such as Porphyromonas gingivalis and Tannerella forsythia. ${ }^{21}$ Additionally, increased antibody responses to Aggregatibacter actinomycetemcomitans, Prevotella intermedia, and Campylobacter rectus have been determined in AgP patients. ${ }^{22}$ When severe periodontal tissue loss in $\mathrm{AgP}$ patients is taken into consideration, the high periodontal clinical measurements found in this study can be considered to be the expected results.

Study has shown that MRP-8 and MRP-14 proteins are involved in antimicrobial activities. ${ }^{4} \mathrm{MRP}-8$ has shown chemotactic effects on for the migration of periodontal ligament cells. ${ }^{23}$ When evaluated in the literature, there were positive correlations among MRP- 8 and the severity of periodontitis. ${ }^{24}$

According to the literature, Lundy et al. ${ }^{10}$ determined the MRP-8 levels in GCF samples from chronic periodontitis patients using different methods, and they found that MRP-8 was a major protein in inflammatory exudates from chronic periodontitis patients. Que et al. ${ }^{25}$ collected GCF samples from patients on different periodontal treatment days and they determined the levels of MRP-8 and MRP-14. In their study, the inflammatory response to plaque accumulation in the patients depended on the initial status of the patients, which might not be equalized by the introduction of perfect oral hygiene. In our study, the patients were grouped and compared in terms of SAgP, AgP, SCP, CP, SG, and G. Our observations were similar to previous studies. MRP-8 and MRP-14 levels in patients with $\mathrm{AgP}$ (smoker and non-smoker) were significantly higher than in CP (smoker and non-smoker) patients. These higher levels of MRP-8 and MRP-14 in patients with AgP are thought to be a consequence of increased secretion from endothelial cells due to damage to periodontally diseased tissues. The microorganism lipopolysaccharides in the dental plaque are potent stimulators of MRP-8 and MRP-14 secretion from periodontal tissue. In periodontal diseases, the periodontal pocket epithelium has more contact with microorganisms compared with healthy pocket epithelium. As a result of this contact, more antimicrobial peptides are released from the pocket epithelium cells to the GCF. It is thought that, as a result of increased tissue destruction, more MRP-8 and MRP-14 known as $\mathrm{Ca}^{2+}$ binding antimicrobial peptides are released from cells into the GCF. The roles of MRP-8 and MRP-14 in the pathogenesis of periodontal diseases and their contributions to periodontal treatment have 
not been precisely determined. It is possible that MRP-8 and MRP-14 are important molecules in the balance of the oral micoflora. Increase in the amount of MRP-8 and MRP-14 in GCF could be due to the presence of leukocytes in the inflamed tissue and in epithelial cells. GCF, along with MRP-8 and MRP-14, based on their antimicrobial activity, might have a protective effect against periodontal pathogenic microorganismsin the gingival sulcus.

During this study Ramfjord sample teeth have been chosen when GCF samples were being taken. The Ramfjord index has an advantage of involving six instead of the ten CPITN teeth, potentially shortening the examination time by almost half. ${ }^{26}$ The teeth mentioned in the Ramfjord index are teeth which reflect the state of the teeth in the whole mouth. There are studies which show that by choosing these teeth, results which reflect the state of the whole mouth can be given. ${ }^{26,27}$ In one of these studies, Mumghamba et al. ${ }^{26}$ in 2004 concluded that there is high agreement between Ramfjord teeth and full mouth. There are also several studies where Ramfjord sample teeth are chosen during GCF sampling. ${ }^{28,29}$ Ramfjord sample teeth have been preferred for GCF sampling in this study by benefiting from these studies.

There are some limitations of this study. When these limitations are examined; patient groups consist of $\mathrm{AgP}, \mathrm{CP}$, and $\mathrm{G}$ groups. The addition of periodontal healthy group in this study could enable us to compare to discuss differently. In addition, patient from smoking groups are not separated by passive smokers or not. During the receipt of GCF samples, Ramfjord sample teeth is preferred. Instead of Ramfjord sample teeth GCF sample were taken from all the teeth. When we discuss why MRP- 8 and MRP-14 levels were higher in AgP group than

\section{References}

1. Berridge MJ, Lipp P, Bootman MD. The versatility and universality of calcium signalling. Nat Rev Mol Cell Biol. 2000;1(1):11-21. doi:10.1038/35036035

2. MacLennan DH. Ca2+ signalling and muscle disease. Eur J Biochem. 2000;267(17):5291-7. doi:10.1046/j.1432-1327.2000.01566.x

3. Donato R. S100: a multigenic family of calcium-modulated proteins of the EF-hand type with intracellular and
$\mathrm{CP}$ group; we will see that the AgP patients are showed more tissue destruction in periodontal tissues. Among the sources of increased tissue destruction, it is known that there is an increased Gram-negative microorganism profile. Alterations in the microorganism profile to Gram-negative microorganisms and increased tissue destruction may be among the known reasons for higher levels of MRP-8 and MRP-14 in AgP groups. When smoker $\mathrm{AgP}$ and $\mathrm{CP}$ groups are compared with the same disease groups with non-smoker patients, it has been observed that smoking decreased the MRP-8 and MRP-14 levels in GCF. Smoking affects MRP-8 and MRP-14 levels and may inhibit the antimicrobial efficiency against microorganisms. Due to these reasons, SAgP patients need to be treated detailed and their maintenance durations should be shortened.

\section{Conclusion}

Smoking inhibits the release of MRP-8 and MRP-14 from cells and inhibits the haemostasis of $\mathrm{Ca}^{2+}$ and damages the neutrophile migration. With further studies, comparing the MRP-8 and MRP-14 levels in GCF in different periodontal diseases with and without smoking prior to treatment and post treatment, and following the determination of the changes in the microorganism structures in the same patients, it is thought that the relationships between the abovementioned antimicrobial peptides and periodontal diseases could be understood more easily.

\section{Acknowledgments}

This study was self-funded by the authors and by the University of Yuzuncu Yil University (Committee of Research no. 2010-DF-B010).

extracellular functional roles. Int J Biochem Cell Biol. 2001;33(7):637-68. doi:10.1016/S1357-2725(01)00046-2

4. Miyasaki KT, Bodeau AL, Murthy AR, Lehrer RI. In vitro antimicrobial activity of the human neutrophil cytosolic S-100 protein complex, calprotectin, against Capnocytophaga sputigena. J Dent Res. 1993;72(2):517-23. doi:10.1177/00220345930720020801 
5. Zasloff M. Antimicrobial peptides in health and disease. $\mathrm{N}$ Engl J Med. 2002;347(15):1199-200. doi:10.1056/NEJMe020106

6. Bender JS, Thang H, Glogauer M. Novel rinse assay for the quantification of oral neutrophils and the monitoring of chronic periodontal disease. J Periodontal Res. 2006;41(3):214-20. doi:10.1111/j.1600-0765.2005.00861.x

7. Eversole LR, Miyasaki KT, Christensen RE. The distribution of the antimicrobial protein, calprotectin, in normal oral keratinocytes. Arch Oral Biol. 1992;37(11):963-8. doi:10.1016/0003-9969(92)90068-J

8. Barthe C, Figarella C, Carrère J, Guy-Crotte O. Identification of 'cystic fibrosis protein' as a complex of two calcium-binding proteins present in human cells of myeloid origin. Biochim Biophys Acta. 1991;1096(2):175-7. doi:10.1016/0925-4439(91)90057-G

9. Kojima T, Andersen E, Sanchez JC, Wilkins MR, Hochstrasser DF, Pralong WF, et al. Human gingival crevicular fluid contains MRP8 (S100A8) and MRP14 (S100A9), two calcium-binding proteins of the S100 family. J Dent Res. 2000;79(2):740-7. doi:10.1177/00220345000790020701

10. Lundy FT, Chalk R, Lamey PJ, Shaw C, Linden GJ. Identification of MRP-8 (calgranulin A) as a major responsive protein in chronic periodontitis. J Pathol. 2000;192(4):540-4. doi:10.1002/1096-9896(2000)9999:9999<::AID-PATH740>3.0.CO;2-1

11. Strasser F, Gowland PL, Ruef C. Elevated serum macrophage inhibitory factor-related protein (MRP) 8/14 levels in advanced HIV infection and during disease exacerbation. J Acquir Immune Defic Syndr Hum Retrovirol. 1997;16(4):230-8. doi:10.1097/00042560-199712010-00002

12. Yui S, Nakatani Y, Mikami M. Calprotectin (S100A8/S100A9), an inflammatory protein complex from neutrophils with a broad apoptosis-inducing activity. Biol Pharm Bull. 2003;26(6):753-60. doi:10.1248/bpb.26.753

13. Bergström J. Cigarette smoking as risk factor in chronic periodontal disease. Community Dent Oral Epidemiol. 1989;17(5):245-7. doi:10.1111/j.1600-0528.1989.tb00626.x

14. Mahanonda R, Sa-Ard-Iam N, Eksomtramate M, Rerkyen $\mathrm{P}$, Phairat B, Schaecher KE, et al. Cigarette smoke extract modulates human beta-defensin-2 and interleukin-8 expression in human gingival epithelial cells. J Periodontal Res. 2009;44(4):557-64. doi:10.1111/j.1600-0765.2008.01153.x

15. Ertugrul AS, Sahin H, Dikilitas A, Alpaslan NZ, Bozoğlan A, Tekin Y. Gingival crevicular fluid levels of human beta-defensin-2 and cathelicidin in smoker and nonsmoker patients: a cross-sectional study. J Periodontal Res. 2014;49(3):282-9. doi:10.1111/jre.12105

16. Nakamura S, Saitoh M, Yamazaki M, Nishimura M, Kurashige $Y$, Arakawa T et al. Nicotine induces upregulated expression of beta defensin-2 via the p38MAPK pathway in the HaCaT human keratinocyte cell line. Med Mol Morphol. 2010;43(4):204-10. doi:10.1007/s00795-010-0493-4
17. Armitage GC. Development of a classification system for periodontal diseases and conditions. Ann Periodontol. 1999;4(1):1-6. doi:10.1902/annals.1999.4.1.1

18. Silness J, Löe H. Periodontal disease in pregnancy. II. correlation between oral hygiene and periodontal condtion. Acta Odontol Scand. 1964;22(1):121-35. doi:10.3109/00016356408993968

19. Löe H, Silness J. Periodontal Disease in Pregnancy. I. Prevalence and Severity. Acta Odontol Scand. 1963;21(6):533-51. doi:10.3109/00016356309011240

20. Kinane DF, Bartold PM. Clinical relevance of the host responses of periodontitis. Periodontol 2000. 2007;43(1):278-93. doi:10.1111/j.1600-0757.2006.00169.x

21. Schenkein HA, Van Dyke TE. Early-onset periodontitis: systemic aspects of etiology and pathogenesis. Periodontol 2000. 1994;6(1):7-25. doi:10.1111/j.1600-0757.1994.tb00023.x

22. Tonetti MS, Mombelli A. Early-onset periodontitis. Ann Periodontol. 1999;4(1):39-53. doi:10.1902/annals.1999.4.1.39

23. Nishimura F, Terranova VP. Comparative study of the chemotactic responses of periodontal ligament cells and gingival fibroblasts to polypeptide growth factors. J Dent Res. 1996;75(4):986-92. doi:10.1177/00220345960750041401

24. Ren XY, Xu L, Meng HX, Zhao HS, Lu RF, Chen ZB, et al. Family-based association analysis of S100A8 genetic polymorphisms with aggressive periodontitis. J Periodontal Res. 2009;44(2):184-92. doi:10.1111/j.1600-0765.2008.01103.x

25. Que ML, Andersen E, Mombelli A. Myeloid-related protein (MRP)8/14 (calprotectin) and its subunits MRP8 and MRP14 in plaque-induced early gingival inflammation. J Clin Periodontol. 2004;31(11):978-84. doi:10.1111/j.1600-051X.2004.00594.x

26. Mumghamba EG, Pitiphat W, Matee MI, Simon E, Merchant AT. The usefulness of using Ramfjord teeth in predicting periodontal status of a Tanzanian adult population. J Clin Periodontol. 2004;31(1):16-8. doi:10.1111/j.0303-6979.2004.00430.x

27. Dowsett SA, Eckert GJ, Kowolik MJ. The applicability of halfmouth examination to periodontal disease assessment in untreated adult populations. J Periodontol. 2002;73(9):975-81. doi:10.1902/jop.2002.73.9.975

28. Ertugrul AS, Sahin H, Dikilitas A, Alpaslan N, Bozoglan A. Comparison of CCL28, interleukin-8, interleukin$1 \beta$ and tumor necrosis factor-alpha in subjects with gingivitis, chronic periodontitis and generalized aggressive periodontitis. J Periodontal Res. 2013;48(1):44-51. doi:10.1111/j.1600-0765.2012.01500.x

29. Ertugrul AS, Sahin H, Dikilitas A, Alpaslan N, Bozoglan A. Evaluation of beta-2 microglobulin and alpha-2 macroglobulin levels in patients with different periodontal diseases. Aust Dent J. 2013;58(2):170-5. doi:10.1111/adj.12022 